\title{
Prosthodontic, Periodontal, and Other Common Needs of Older Adults Seeking Treatment at a Canadian Dental School: A 30-year Comparison
}

\author{
Vincent Torresyap ${ }^{1}$, Jay Hoover ${ }^{2}$, Chandima Karunanayake ${ }^{3}$, Josh Rae ${ }^{4}$, Ken Tomchuck ${ }^{5}$
}

\begin{abstract}
Aims and objectives: To assess the needs of older adults over the age of 65 currently attending a university-based dental clinic and to compare the findings with a similar study done at the same locale, approximately 30 years ago.

Materials and methods: Electronic records of patients aged 65 years and over, accepted for treatment at the clinic during the period 2015 and 2016 were reviewed and the following information obtained: gender, marital status, habits such as smoking, health history, current medication, chief complaint, missing teeth, and the treatment needs. Hard tissue abnormalities were recorded if the chart contained a recent panoramic radiograph. The findings were compared to those obtained from patients over 65 years of age, at this institution almost three decades ago.

Results: Older patients seeking care at this university dental clinic required less need for removable complete, and partial dentures and periodontal surgical procedures but more fixed prosthesis than a similarly aged cohort of patients visiting this same institution nearly 30 years ago.

Conclusion: Practicing dentists must be cognizant of the changing trends in needs in this increasing population group. Further, dental school curriculums must reflect the current realities in oral needs among older adults, integrating innovative changes in education utilizing an interdisciplinary approach.

Keywords: Canadian dental school, Older adults, Periodontics, Prosthodontics, Treatment needs.

International Journal of Experimental Dental Science (2019): 10.5005/jp-journals-10029-1186
\end{abstract}

\section{INTRODUCTION}

The Canadian population is aging rapidly. The percentage of those 65 years and above has been projected to rise from 14 in 2009 to about 24 by $2036 .{ }^{1}$ In 2015, Canadians over 65 years and older, for the first time, outnumbered children 14 years or younger, according to a recent Canadian census report. ${ }^{2}$ Similar trends in other developed nations have raised concerns over the looming demand for health services and the associated costs involving older adults. ${ }^{3}$ Those born between 1946 and 1964 and labeled baby boomers are quickly entering their senior years, retaining more of their natural teeth and therefore, possibly requiring more oral healthcare and having greater needs than the current seniors. ${ }^{4,5}$

In the past, older patients have sought attention at a dental school teaching facility for a variety of reasons. The most important was and still is the relatively lower cost of treatment as most patients seeking care at these institutions tend to have low-income levels and possibly lack dental insurance. ${ }^{6}$

Among the dental services provided at the teaching institutions, removable prosthodontics (21.4\%), operative and endodontics (23.4\%), and oral surgery (12.3\%) appear to be utilized the most. ${ }^{7}$ In a study done at the University of Saskatchewan, Canada, during 1986-1988, it was determined that $42 \%$ of the elderly patients that visited the school clinic were edentulous, and the majority of these patients were destined for a new full denture or a reline of an existing denture. ${ }^{8}$ This same study also described other treatment needs of dentate patients including plaque control and scaling (49.4\%), extractions (29.2\%), periodontal surgery $(37.1 \%)$, endodontics $(23.6 \%)$, fixed prosthodontics (25.8\%), and dental restorations (40.4\%). However, the emerging or new older population groups in Canada and other developed

\begin{abstract}
${ }^{1}$ Department of Prosthodontics, College of Dentistry, University of Saskatchewan, Saskatoon, Canada

${ }^{2}$ Department of Prosthodontics, College of Dentistry, Periodontics, University of Saskatchewan, Saskatoon, Canada

${ }^{3}$ Canadian Centre for Health and Safety in Agriculture, University of Saskatchewan, Saskatoon, Canada

${ }^{4,5}$ College of Dentistry, University of Saskatchewan, Saskatoon, Canada Corresponding Author:Vincent Torresyap, Department of Prosthodontics, College of Dentistry, University of Saskatchewan, Saskatoon, Canada, Phone: +1 3069665087, e-mail: vincent.torresyap@usask.ca
\end{abstract}

How to cite this article: Torresyap V, Hoover J, Karunanayake C, et al. Prosthodontic, Periodontal, and Other Common Needs of Older Adults Seeking Treatment at a Canadian Dental School: A 30-year Comparison. Int J Experiment Dent Sci 2019;8(1):1-5.

Source of support: Nil

Conflict of interest: None

countries will likely differ from previous generations of older adults with respect to a longer life span and higher disposable income, retaining more of their natural teeth and having better access to oral care. In addition, this group of older adults could be on multiple prescription medications, have greater access to oral health information via the Internet and other social media, and have different treatment needs and expectations compared to their predecessors, thus presenting a different set of issues to the oral health provider. ${ }^{9}$ Treatment needs will most likely tend to focus on preventative and maintenance care with regard to plaque control in both natural and fixed prosthetic teeth, while the need for selected periodontal surgical procedures such as mucogingival 
Prosthodontic, Periodontal, and Other Common Needs of Older Adults Seeking Treatment at a Canadian Dental School

surgery and crown lengthening, adult orthodontics, complex fixed restorations, implant therapy and cosmetic procedures such as tooth whitening will increase. Consequently, the changing trends in the oral health and needs of the growing population of emerging older adults should become a focus of dental school curriculums and a priority for practicing dentists. ${ }^{10}$ Oral health professionals must be cognizant of these changing needs and be competent to provide adequate care to this rapidly expanding segment of the Canadian population. ${ }^{11}$

The aim of the present study was to assess the needs of a group of older adults over the age of 65 currently attending the dental clinic at the University of Saskatchewan and to compare the findings with a similar study done at the same locale, approximately 30 years ago.

\section{Materials and Methods}

A review of the electronic records of all patients aged 65 years and over, accepted for treatment at the dental clinic, University of Saskatchewan in Saskatoon, SK, Canada, during the period 2015 and 2016 was undertaken. The general criteria for acceptance as a patient at this dental school are that the individual should be in reasonably good health, ambulatory, functionally independent, and have oral needs that can be managed by students. The following information was obtained: gender, health history, current medication, chief complaint, and treatment needs. Hard tissue abnormalities were recorded if the chart contained a recent panoramic radiograph. The patient was identified only by the chart number. The name was not entered on any recording form, ensuring anonymity. The findings were then compared to those obtained from patients over 65 years of age, at this institution almost three decades ago (1986-1988). ${ }^{8}$

\section{Statistical Analysis}

Statistical analyses were conducted using SPSS version 24 (IBM SPSS Statistics for Windows, 2015.: IBM Corp., Armonk, NY). Descriptive results were presented using frequencies and percentages for categorical variables, and measures of central tendencies (mean) and measures of variation (standard deviation and range) were reported for continuous variables. Two periods (1986-1988 and 2015-2016) were compared using $Z$ test for two proportions. ${ }^{12}$ Statistical significance was reported using $5 \%$ level of significance.

The study was conducted in full accordance with the ethical principles and with the approval of the University of Saskatchewan, Biomedical Research Ethics Board.

\section{Results}

A total 280 charts of patients 65 years and above [mean age 74.20 \pm 6.89 (standard deviation) with a range of 66 to 94 years] (males 158 and females 122) seeking care at the University Dental Clinic in Saskatoon, Saskatchewan, were reviewed during the period 2015 and 2016. A total of 156 patients ( 89 males and 67 females) between the age of 65 and 89 sought care during 1986-1988 period. The mean number of natural teeth present in the 2015-2016 sample was $14.31 \pm 11.06$ (standard deviation). The majority either lived in Saskatoon or lived within a short driving distance from the city. Just over $70 \%$ of the sample indicated having one or more health concerns, with cardiac and endocrine issues accounting for $32.9 \%$ (Table 1). The majority of medications consumed by the present sample was directed to the control of hypertension, cardiacrelated problems, and anticoagulants. The health conditions and
Table 1: Health conditions and medications used reported by patients upon visiting dental clinics in 2015-2016, gender wise

\begin{tabular}{|c|c|c|c|}
\hline & $\begin{array}{l}\text { Male } \\
(n=158)\end{array}$ & $\begin{array}{l}\text { Female } \\
(n=122)\end{array}$ & $\begin{array}{l}\text { Total } \\
(n=280)\end{array}$ \\
\hline & $n(\%)$ & $n(\%)$ & $n(\%)$ \\
\hline \multicolumn{4}{|l|}{ Health conditions } \\
\hline Carcinoma & $16(10.1)$ & $8(6.6)$ & $24(8.6)$ \\
\hline Cardiac & $36(22.8)$ & $18(14.8)$ & $54(19.3)$ \\
\hline Orthopedic & $17(10.8)$ & $7(5.7)$ & $24(8.6)$ \\
\hline Endocrine & $17(10.8)$ & $21(17.2)$ & $38(13.6)$ \\
\hline Respiratory & $6(3.8)$ & $5(4.1)$ & $11(3.9)$ \\
\hline Gastrointestinal & $10(6.3)$ & $8(6.6)$ & $18(6.4)$ \\
\hline Dermatological & $1(0.6)$ & $0(0.0)$ & $1(0.4)$ \\
\hline Allergies & $8(5.1)$ & $9(7.4)$ & $17(6.1)$ \\
\hline Other & $8(5.1)$ & $10(8.2)$ & $18(6.4)$ \\
\hline \multicolumn{4}{|l|}{ Medication used } \\
\hline Analgesics & $23(14.6)$ & $9(7.4)$ & $32(11.4)$ \\
\hline Hypertensive & $75(47.5)$ & $59(48.4)$ & $134(47.9)$ \\
\hline Cardiac & $73(46.2)$ & $48(39.3)$ & $121(43.2)$ \\
\hline Diuretics & $30(19.0)$ & $21(17.2)$ & $51(18.2)$ \\
\hline Antidepression & $17(10.8)$ & $17(13.9)$ & $34(12.1)$ \\
\hline Anticonvulsant & $1(0.6)$ & $5(4.1)$ & $6(2.1)$ \\
\hline Sedatives & $3(1.9)$ & $5(4.1)$ & $8(2.9)$ \\
\hline Anticoagulant & $63(39.9)$ & 24 (19.7) & $87(31.1)$ \\
\hline Hormones & $17(10.8)$ & $28(23.0)$ & 45 (16.1) \\
\hline
\end{tabular}

medications were not recorded in the 1986-1988 period and hence were not available for comparison. Table 2 compares the chief complaints, while Tables 3 and 4 pertain to the recommended treatment plans as presented in 1986-1988 and in 2015-2016.

\section{Prosthodontic Related}

Denture-related complaints were statistically less in 2015-2016 compared to 1986-1988, whereas more individuals complained of painful teeth and lost restorations in 2015-2016 vs 1986-1988. The treatment needs of the edentulous and dentate patients are presented in Tables 3 and 4, respectively. Once the patient has been accepted for treatment, their needs are assessed and recorded in the diagnostic clinic by a senior dental student and a supervising dentist. Significantly less need was observed for full and partial removable dentures on both arches in 2015-2016 compared to 30 years ago. However, a significant need was observed for single crowns on posterior teeth in 2015-2016 compared to 1986-1988. Dental implants were not carried out in 1986-1988 at this institution and hence cannot be compared. During the 2015-2016 academic year, 44 patients were screened for posterior single-tooth implants and 39 were accepted for treatment. Anterior implants are not carried out at this dental school due to the complex nature of implant crown restorations.

\section{Periodontal Related}

No significant differences were observed in chief complaints related to gingival bleeding on brushing, mobile, or sensitive teeth, in both groups (1986-1988 and 2015-2016). Plaque control, scaling, and root planning continued to be the highest need in both groups, and no statistical difference was observed. In the 1986-1988 group, the periodontal surgical procedures were more often planned treatment compared to the present sample $(p<0.0001)$. 
Prosthodontic, Periodontal, and Other Common Needs of Older Adults Seeking Treatment at a Canadian Dental School

Table 2: Chief complaints reported by patients upon visiting dental clinic in 1986-1988 and 2015-2016

\begin{tabular}{|c|c|c|c|c|c|c|c|c|c|}
\hline \multirow[b]{3}{*}{ Chief complaint } & \multicolumn{2}{|c|}{ Male } & & \multicolumn{2}{|c|}{ Female } & \multicolumn{3}{|c|}{ Total } & \multirow[b]{3}{*}{$p$ value } \\
\hline & $\begin{array}{l}2015-2016 \\
(n=158)\end{array}$ & $\begin{array}{l}1986-1988 \\
(n=89)\end{array}$ & & $\begin{array}{l}2015-2016 \\
(n=122)\end{array}$ & $\begin{array}{l}1986-1988 \\
(n=67)\end{array}$ & & $\begin{array}{l}2015-2016 \\
(n=280)\end{array}$ & $\begin{array}{l}1986-1988 \\
(n=156)\end{array}$ & \\
\hline & $n(\%)$ & $n(\%)$ & $p$ value & $n(\%)$ & $n(\%)$ & $p$ value & $n(\%)$ & $n(\%)$ & \\
\hline $\begin{array}{l}\text { Denture } \\
\text { problem }\end{array}$ & $50(31.6)$ & $43(48.3)$ & 0.009 & $41(33.6)$ & $28(41.8)$ & 0.263 & $91(32.5)$ & $71(45.5)$ & 0.006 \\
\hline Checkup & $21(13.3)$ & $18(20.2)$ & 0.153 & 24 (19.7) & $17(25.4)$ & 0.363 & $45(16.1)$ & 35 (22.4) & 0.099 \\
\hline $\begin{array}{l}\text { Chewing } \\
\text { difficulties }\end{array}$ & $9(5.7)$ & $2(2.2)$ & 0.208 & $8(6.6)$ & $3(4.3)$ & 0.562 & $17(6.1)$ & $5(3.2)$ & 0.190 \\
\hline Painful tooth & $38(24.1)$ & $10(11.2)$ & 0.015 & $22(18.0)$ & $4(6.0)$ & 0.021 & $60(21.4)$ & $14(9.0)$ & 0.001 \\
\hline Bleeding gums & $1(0.6)$ & $1(1.1)$ & 0.682 & $0(0.0)$ & $2(3.0)$ & 0.055 & $1(0.4)$ & $3(1.9)$ & 0.101 \\
\hline Cleaning & $2(1.3)$ & $0(0.0)$ & 0.285 & $4(3.3)$ & $3(4.5)$ & 0.674 & $6(2.1)$ & $3(1.9)$ & 0.881 \\
\hline Worn teeth & $7(4.4)$ & $4(4.5)$ & 0.984 & $2(1.6)$ & $3(4.5)$ & 0.246 & $9(3.2)$ & $7(4.5)$ & 0.496 \\
\hline Broken tooth & - & $4(4.5)$ & - & - & $2(3.0)$ & - & - & $6(3.8)$ & - \\
\hline Decay & $9(5.7)$ & - & - & - & - & - & $16(5.7)$ & - & - \\
\hline Lost filling & $21(13.3)$ & $3(3.4)$ & 0.011 & $13(10.7)$ & $3(4.5)$ & 0.144 & $34(12.1)$ & $6(3.8)$ & 0.004 \\
\hline Loose tooth & $6(3.8)$ & $3(3.4)$ & 0.865 & $0(0.0)$ & $1(1.5)$ & 0.177 & $6(2.1)$ & $4(2.6)$ & 0.779 \\
\hline Tooth sensitivity & $0(0.0)$ & - & - & $0(0.0)$ & - & - & $0(0.0)$ & - & - \\
\hline Other & $2(1.3)$ & $1(1.1)$ & 0.920 & $0(0.0)$ & $1(1.5)$ & 0.177 & $2(0.7)$ & $2(1.3)$ & 0.548 \\
\hline
\end{tabular}

Table 3: Prosthetic needs of complete and partially edentulous patients upon visiting dental clinic in 1986-1988 and 2015-2016, gender wise

\begin{tabular}{|c|c|c|c|c|c|c|c|c|c|}
\hline \multirow[b]{3}{*}{ Treatment } & \multicolumn{2}{|c|}{ Male } & & \multicolumn{2}{|c|}{ Female } & \multirow[b]{3}{*}{$p$ value } & \multicolumn{2}{|c|}{ Total } & \multirow[b]{3}{*}{$p$ value } \\
\hline & $\begin{array}{l}2015-2016 \\
(n=158)\end{array}$ & $\begin{array}{l}1986-1988 \\
(n=89)\end{array}$ & \multirow[b]{2}{*}{$p$ value } & $\begin{array}{l}2015-2016 \\
(n=122)\end{array}$ & $\begin{array}{l}1986-1988 \\
(n=67)\end{array}$ & & \multirow{2}{*}{$\begin{array}{l}2015-2016 \\
(n=280)\end{array}$} & \multirow{2}{*}{$\begin{array}{l}1986-1988 \\
(n=156)\end{array}$} & \\
\hline & $n(\%)$ & $n(\%)$ & & $n(\%)$ & $n(\%)$ & & & & \\
\hline \multicolumn{10}{|l|}{ Full dentures } \\
\hline Both arches & $34(21.5)$ & $40(44.9)$ & 0.0001 & $34(27.9)$ & $24(35.8)$ & 0.258 & $68(24.3)$ & $64(41.0)$ & 0.0003 \\
\hline Upper arch & $19(12.0)$ & $9(10.1)$ & 0.645 & $12(9.8)$ & $8(11.9)$ & 0.653 & $31(11.1)$ & $17(10.9)$ & 0.952 \\
\hline Lower arch & $(0.0)$ & $1(1.1)$ & 0.180 & $0(0.0)$ & $1(1.5)$ & 0.177 & $0(0.0)$ & $2(1.3)$ & 0.057 \\
\hline \multicolumn{10}{|c|}{ Partial dentures } \\
\hline Both arches & $12(7.6)$ & $11(12.4)$ & 0.215 & $11(9.0)$ & $11(16.4)$ & 0.128 & $23(8.2)$ & $22(14.1)$ & 0.052 \\
\hline Upper arch & $6(3.8)$ & $5(5.6)$ & 0.503 & $3(2.5)$ & $2(3.0)$ & 0.826 & $9(3.2)$ & $7(4.5)$ & 0.496 \\
\hline Lower arch & $28(17.7)$ & $13(14.6)$ & 0.529 & $13(10.7)$ & 12 (17.9) & 0.158 & $41(14.6)$ & $25(16.0)$ & 0.696 \\
\hline
\end{tabular}

\section{Other}

In 1986-1988 group, more males required endodontic therapy compared to those in $2015-2016$ ( $p=0.038$ ). No statistically significant differences were observed in procedures such as extractions, anterior crowns, and operative dentistry in the two periods under comparison. At this dental clinic, panoramic or full-mouth series radiographs are not routinely taken on all new patients who present for treatment unless indicated, and hence radiographic abnormalities and periodontal bone loss were not included in the study. Painful teeth, probably attributable to caries or pulpitis ( $p=0.001)$, and lost restorations ( $p=0.004)$ were presumably more prevalent in the current population compared to those in 1986-1988.

\section{Discussion}

The current study attempted to document the chief complaint and the treatment needs of older adults seeking care at the Dental Clinic, University of Saskatchewan during the 2015-2016 academic year and to observe changes in trends, if any, in a similar study conducted nearly 30 years ago at the same institution. The study was initiated to document the oral health needs among the growing population of Canadians 65 years and older living in the City of Saskatoon, Saskatchewan, Canada. Approximately $10 \%{ }^{13}$ of the Canadian population was over 65 in 1981; whereas three decades later, the population increased to approximately $16.1 \%{ }^{2}$ No effort was made to compare the perceived needs of this group of older adults, which is largely affected by their social-economic status and perceptions toward oral health, ${ }^{14}$ with the needs as assessed after the intraoral evaluation. Although one cannot assume that the oral health conditions of those actively seeking care at teaching institutions reflect the dental status and needs of older persons in the general population, the findings may be compared to the needs of older adults attending university-based teaching institutions in other locales. Data obtained from the health questionnaire revealed that cardiac, endocrine-related, and orthopedic issues predominated the medical conditions affecting the present sample of older patients. This trend has not changed in 30 years as these disorders were observed in another study carried out at the same institution among patients between the age of 65 
Prosthodontic, Periodontal, and Other Common Needs of Older Adults Seeking Treatment at a Canadian Dental School

Table 4: Treatment needs of dentate patients upon visiting dental clinic in 1986-1988 and 2015-2016, gender wise

\begin{tabular}{|c|c|c|c|c|c|c|c|c|c|}
\hline \multirow[b]{3}{*}{ Treatment needs } & \multicolumn{2}{|c|}{ Male } & \multicolumn{3}{|c|}{ Female } & \multicolumn{3}{|c|}{ Total } & \multirow[b]{3}{*}{$p$ value } \\
\hline & $\begin{array}{l}2015-2016 \\
(n=158)\end{array}$ & $\begin{array}{l}1986-1988 \\
(n=89)\end{array}$ & \multirow[b]{2}{*}{$p$ value } & $\begin{array}{l}2015-2016 \\
(n=122)\end{array}$ & $\begin{array}{l}1986-1988 \\
(n=67)\end{array}$ & \multirow[b]{2}{*}{$p$ value } & $\begin{array}{l}2015-2016 \\
(n=280)\end{array}$ & $\begin{array}{l}1986-1988 \\
(n=156)\end{array}$ & \\
\hline & $n(\%)$ & $n(\%)$ & & $n(\%)$ & $n(\%)$ & & $n(\%)$ & $n(\%)$ & \\
\hline PC and SRP & $93(58.9)$ & $44(49.4)$ & 0.153 & $64(52.5)$ & $36(53.7)$ & 0.865 & $157(56.1)$ & $80(51.3)$ & 0.337 \\
\hline Routine extraction & $39(24.7)$ & $26(29.2)$ & 0.435 & $22(18.0)$ & $18(26.9)$ & 0.156 & $61(21.8)$ & $44(28.2)$ & 0.134 \\
\hline Operative & $84(53.2)$ & $36(40.4)$ & 0.055 & $54(44.3)$ & $34(50.7)$ & 0.395 & $138(49.3)$ & $70(44.9)$ & 0.379 \\
\hline $\begin{array}{l}\text { Single crown- } \\
\text { anterior }\end{array}$ & $6(3.8)$ & $2(2.2)$ & 0.509 & $6(4.9)$ & $2(3.0)$ & 0.529 & $12(4.3)$ & $4(2.7)$ & 0.352 \\
\hline $\begin{array}{l}\text { Single crown- } \\
\text { posterior }\end{array}$ & $30(19.0)$ & $4(4.5)$ & 0.002 & $24(19.7)$ & $1(1.5)$ & 0.0004 & $54(19.3)$ & $5(3.2)$ & $<0.0001$ \\
\hline Endo & $21(13.3)$ & $21(23.6)$ & 0.038 & $11(9.0)$ & $6(9.0)$ & 0.992 & $32(11.4)$ & $27(17.3)$ & 0.085 \\
\hline Periodontal surgery & $6(3.8)$ & $33(37.1)$ & $<0.0001$ & $3(2.5)$ & $29(43.3)$ & $<0.0001$ & $9(3.2)$ & $62(39.7)$ & $<0.0001$ \\
\hline Implants & $4(2.5)$ & - & - & $3(2.5)$ & - & - & $7(2.5)$ & - & - \\
\hline $\begin{array}{l}\text { Impacted teeth (extrac- } \\
\text { tion) }\end{array}$ & $0(0.0)$ & $2(2.2)$ & 0.059 & $1(0.8)$ & $1(1.5)$ & 0.667 & $1(0.4)$ & $3(1.9)$ & 0.101 \\
\hline Alveolectomy/plasty & $0(0.0)$ & $1(1.1)$ & 0.180 & $0(0.0)$ & $2(3.0)$ & 0.004 & $0(0.0)$ & $3(1.9)$ & 0.019 \\
\hline Other treatment & $7(4.4)$ & $0(0.0)$ & 0.044 & $3(2.5)$ & $5(7.5)$ & 0.055 & $10(3.6)$ & $5(3.2)$ & 0.841 \\
\hline
\end{tabular}

and $89 .{ }^{15}$ However, concerning medications, more anticoagulants and diuretics and less analgesics were being prescribed in the present group compared to 30 years ago. Oral examinations of the older patients must include the soft tissues as changes may manifest in these tissues as a side effect of concomitant drug therapy or an oral manifestations of a medical condition. Further, due to the high prevalence of anticoagulant use, it is prudent to peruse the medical history carefully prior to performing any type of periodontal or oral surgery in the older patient. Lately, there has been an exponential growth in the use of dietary supplements and natural health products among the general population in the United States and Canada. ${ }^{16-18} \mathrm{~A}$ health history should include a listing of all, over-the-counter nutritional products because the wide usage of supplements resulted in some concerns regarding the safety of a few of these such as ginkgo biloba, St. John's wort, evening primrose, and valerian as these could potentially interact with medications commonly prescribed to the older patients. ${ }^{19}$ Of those who presented at the dental clinic during the academic year 2015-2016, 16.1\% requested to have a "checkup" and did not perceive to have any dental concerns. These individuals visited the clinic on their own volition and were not referred to the clinic by private dental practitioners or allied health workers. Similar trends were observed in older adults seeking care in 1986-1988.

Edentulism is still an issue worldwide and such patients tend to be smokers, asthmatics, have poor nutrition, and/or are at a risk of specific medical conditions such as atherosclerosis of the coronary arteries, diabetes, and rheumatoid arthritis. ${ }^{20-22}$ The incidence of tooth loss in both developing and developed nations appears to escalate at about 65 years of age. ${ }^{23}$ Just over $24 \%$ of the present sample planned to receive conventional complete removable dentures, which is considerably less than what was planned in 1986$1988(41 \%)(p=0.0003)$. Possible reasons for this difference could be that older adults living a few decades ago preferred to or were recommended to have their affected tooth or teeth extracted rather than attempting to retain the natural teeth for a variety of reasons such as lower disposable income levels, accessibility of dentists in the more rural settings, and the relative lack of technology evident in the modern-day dentistry. Although less patients were in need of complete dentures, it is not known whether there were patients in the present sample who already had well-fitting complete dentures requiring no further treatment. Although well-planned implantsupported overdentures are superior to conventional removable dentures, the latter are still cost-effective and accepted by most, older patients, ${ }^{8}$ as evident by nearly $24 \%$ of the present sample consenting to have a new set of removable complete dentures.

Among the dentate population surveyed, plaque control (PC), scaling and root planning (SRP) were the greatest need (56.1\%) followed by caries control (49.3\%), and these findings are unchanged and similar to the treatment needs three decades ago at this site and other locales in the USA ${ }^{24}$ A noticeable finding was the significant reduction of periodontal surgery in the present cohort (3.2\%) compared to 1986-1988 (39.7\%). The reason for this is uncertain but could be due to the prevailing treatment philosophies at that time specially related to mucogingival surgery. The final decision regarding the performance of periodontal surgery is made when the patient is seen by a senior dental student at the periodontal clinic and after consulting with a specialist. Slightly fewer patients in the current sample required endodontic therapy on at least one tooth compared to 1986-1988 sample though the difference was not statistically significant. Degenerating pulp, cervical or recurrent caries, fractured teeth, and planning for overdentures may be some factors that contributed to nearly $11.4 \%$ requiring endodontics.

Limitations of this study included the relatively low sample size, the lack of full mouth or panoramic radiographs, and at times, incomplete data. Complete periodontal status was not available as comprehensive examinations are only carried out when the patient is seen at the periodontal clinic and not during the diagnostic clinic.

\section{Conclusion}

Older patients seeking care at this university-based dental clinic required less need for removable complete and partial dentures and periodontal surgical procedures but more fixed prosthesis compared to a similarly aged cohort of patients visiting the same institution nearly 30 years ago. As the oral needs of the emerging older patient are predicted to rise, the practicing dentist must not only be aware of the changing trends in such needs, but also 
be mindful of the associated chronic diseases and the myriad of medications that are used to manage these diseases that could potentially influence the treatment of oral diseases. ${ }^{25}$ In addition, the oral health of the older patient should not be overlooked by caregivers, nursing home staff, and family practitioners and should be promoted as part of the overall health. ${ }^{26}$ Dental personnel should take advantage of continuing education courses focused on this group, both from a treatment standpoint and from a communication and psychological standpoint in order to be better prepared to deal with this increasing population group. ${ }^{27}$ Further, dental school curriculums must reflect the changing trends in needs among older adults, integrating innovative changes in education utilizing an interdisciplinary approach. ${ }^{28}$

\section{Clinical Significance}

The study demonstrates the changing trends in the oral health of older adults compared to what was observed about 30 years ago such as a lesser need for removable complete and partial dentures and periodontal surgical procedures and a greater need for fixed prosthesis. Dentists should be mindful of these trends and dental schools should develop a more versatile curriculum to address such changes emerging in this group of adult patients.

\section{References}

1. Statistics Canada. Population Projections for Canada, Provinces and Territories 2009-2036. Catalogue no. 91-520-X, 2010. Available from: https://www150.statcan.gc.ca/n1/pub/91-520-x/91-520-x2010001eng.pdf.

2. Canada's population estimates: Age and sex, July 1, 2015. Available from: https://www.statcan.gc.ca/daily-quotidien/150929/ dq150929b-eng.htm.

3. UN Department of Economic and Social Affairs, Population Division. World Population Ageing, 2007. Available from: http://www.un.org/ en/development/desa/population/publications/pdf/ageing/ WorldPopulationAgeingReport2007.pdf.

4. Report on the Findings of the Oral Health Component of the Canadian Health Measures Survey 2007-2009, 2010. Available from: http:// publications.gc.ca/site/eng/369649/publication.html.

5. Kiyak HA, Reichmuth M. Barriers to and enablers of older adults' use of dental services. J Dent Educ 2005;69(9):975-986.

6. Damiano PC, Warren JJ. A profile of patients in six dental school clinics and implications for the future. J Dent Educ 1995;59(12):1084-1090.

7. Ettinger PL, Beck JD. Geriatric dental curriculum and the needs of the elderly. Spec Care Dentist 1984;4(5):207-213. DOI: 10.1111/j.17544505.1984.tb00189.x.

8. Hoover JN, McDermott RE. Dental treatment needs of elderly patients seen at a university teaching clinic. Am J Dent 1990;3(5):213-216.

9. D'Souza DSJ. Oral health care needs in the geriatric population. In: Mandeep Singh V, ed. Emerging Trends in Oral Health Sciences and Dentistry. InTech; 2015. pp. 305-314. Available from: http://dx.doi. org/10.5772/59246.

10. Petersen PE, Yamamoto T. Improving the oral health of older people: the approach of the WHO global oral health Program.
Comm Dent Oral Epidemiol 2005;33(2):81-92. DOI: 10.1111/j.16000528.2004.00219.x.

11. McNally ME, Matthews DC, Clovis JB, et al. The oral health of ageing baby boomers: a comparison of adults aged $45-64$ and those 65 years and older. Gerodontology 2012;31(2):123-135. DOI: 10.1111/ger.12022. Available from https://doi.org/10.1111/ger.12022.

12. Ott Lynn R, Longnecker M. An Introduction to Statistical Methods and Data Analysis, 6th ed., Brooks/Cole, Cengage Learning; 2010. pp. 507-513.

13. A day in the life: How do older Canadians spend their time? Available from: https://www150.statcan.gc.ca/n1/pub/75-006-x/2018001/ article/54947-eng.htm.

14. Lundegren $\mathrm{N}$. Oral health and self-perceived oral treatment need of adults in Sweden. Swed Dent J Suppl 2012;(223):10-76.

15. McDermott R, Hoover JN. Self-reported medical conditions and drug use among elderly dental patients. J Can Dent Assoc (Tor) 1990;56(3):219-221.

16. Dickinson A, Blatman J, El-Dash N, et al. Consumer usage and reasons for using dietary supplements: Report of a series of surveys. J Am Coll Nutr 2014;33(2):176-182. DOI: 10.1080/07315724.2013.875423.

17. Canadian Community Health Survey, Cycle 2.2, Nutrition (2004). A Guide to Accessing and Interpreting the Data (Catalogue H16420/2006E-PDF). Available from: http://www.hc-sc.gc.ca/fn-an/ surveill/nutrition/commun/index_e.html.

18. Radimer K, Bindewald B, Hughes J, et al. Dietary supplement use by US adults: data from the national health and nutrition examination survey, 1999-2000. Am J Epidemiol 2004;160(4):339-449. DOI: 10.1093/aje/kwh207.

19. Fitzgerald J, Epstein JB, Donaldson M, et al. Outpatient medication use and implications for dental care: guidance for contemporary dental practice. J Can Dent Assoc 2015;81:f10.

20. Kaira LS, Dabral E. Prevalence of complete edentulism among Udaipur population of India. The Saudi Journal for Dental Research 2014;5(2):139-145. DOI: 10.1016/j.ksujds.2013.09.002.

21. Felton D. Edentulism and comorbid factors. J Prosthodont 2009;18(2):88-96. DOI: 10.1111/j.1532-849X.2009.00437.x.

22. Gil-Montoya JA, Ferreira de Mello AL, Barrios R, et al. Oral health in the elderly patient and its impact on general well-being: a nonsystematic review. Clin Interv Aging 2015;10:461-467. DOI: 10.2147/CIA.S54630.

23. Kassebaum NJ, Bernabé $E$, Dahiya $M$, et al. Global burden of severe tooth loss: a systematic review and meta-analysis. J Dent Res 2014;93(7 Suppl 1):205-285. DOI: 10.1177/0022034514537828.

24. Barnes GP, Tollefsbol RG, Parker WA, et al. Care needs of the elderly treated at a dental school. Gerondontology 1986;5(2):129-134. DOI: 10.1111/j.1741-2358.1986.tb00060.x.

25. Lamster IB, Eaves K. A model for dental Practice in the 21st century. Am J Public Health 2011;101(10):1825-1830. DOI: 10.2105/ AJPH.2011.300234.

26. Walsh LJ. Minimal intervention management of the older patient. Br Dent J 2017;223(3):151-161. DOI: 10.1038/sj.bdj.2017.660.

27. Stein PS, Aalboe JA, Savage MW, et al. Strategies for communicating with older dental patients. J Am Dent Assoc 2014;145(2):159-164. DOI: 10.14219/jada.2013.28.

28. León S, Giacaman RA. Reality and challenges of the oral health for older adults in chile and the role of a new discipline: geriatric Dentistry. Rev Med Chil 2016;144(4):496-502. DOI: 10.4067/S003498872016000400011. 